\title{
The Effects of Bridge Exercise with One Hip Joint Adduction on Trunk Muscle Thickness
}

\author{
Jae-Cheol Park', Dong-Kyu Lee \\ 'Department of Physical Therapy, Chunnam Techno University, Gokseong, Republic of Korea; ${ }^{2}$ Department of Physical Therapy, Sunhan Hospital, \\ Gwangju, Republic of Korea
}

Purpose: This study aimed to verify the effects of bridge exercise with resistance to one hip joint adductor muscle on the thickness of external and internal oblique abdominal muscles, transversus abdominis muscle, and erector spinae muscle.

Methods: The subjects were divided into two exercise groups: 15 for Bridge Exercise Group (BEG) and 15 for One Hip joint Adduction Bridge Exercise Group (OHABEG). The study used an ultrasonic instrument to measure trunk muscle thickness. OHABEG performed a bridge exercise with one hip Joint adduction. BEG performed a bridge exercise without resistance.

Results: The external oblique abdominal, internal oblique abdominal, and the transversus abdominis muscles showed a significant increase by period and time in intra-group interactions $(p<0.05)$, while there was no significant difference in inter-group changes $(p>0.05)$. The erector spinae muscle had a significant increase in each period $(p<0.05)$ but no significant difference in time, intra-group interactions, and in inter-group changes ( $p>0.05)$.

Conclusion: These results demonstrated that bridge exercise with one hip joint adduction had positive effects on trunk muscle thickness. These results confirm that a bridge exercise with one hip joint adduction has a positive effect on the muscle thickness of trunk, suggesting the possibility of using it as a rehabilitation treatment for a lumbar stabilization exercise and as a basic data.

Keywords: Bridge exercise, Trunk muscle thickness, Hip joint adduction

\section{INTRODUCTION}

An important element in daily life activities and movements, trunk muscle consists of external oblique (EO) abdominal muscle, internal oblique (IO) abdominal muscle, transversus abdominis (TrA) muscle, as well as erector spinae (ES) muscle., ${ }^{1,2}$ Weakening of the trunk muscle causes dysfunction by reducing its stability and threatening pelvic stability, which negatively affects movements. ${ }^{3-5}$ Thus, it is essential to strengthen trunk muscle to reduce pain and for lumbar pelvis complex to function properly, by carrying out back stabilization, bridge exercise, plank, and quadruped exercise are conducted. ${ }^{6-8}$

Among them, bridge exercise is carried out to solve weakened pelvic muscle or malfunctions of leg due to musculoskeletal disease or nervous system damage, since it gives gravity and weight to the trunk and increases the ability to control posture. ${ }^{9,10}$ Applied in the supine position, back stabi-

Received Nov 12, 2020 Revised Dec 15, 2020

Accepted Dec 21, 2020

Corresponding author Dong-Kyu Lee

E-mail Idkpt@hanmail.net lization exercise is conducted at the beginning of rehabilitation to improve poor postural control ability, and it can train various muscles according to the changing position of support surface and feet. ${ }^{11}$ However, since the bridge exercise focuses on strengthening the hip joint extension muscle and muscle fibers of the spine, it is less effective in strengthening the abdomen than other stabilization exercises. ${ }^{12}$

To improve the effects of bridge exercise, modified bridge exercises have been proposed since a long time ago. Saliba et al. ${ }^{13}$ suggested that bridge exercise on an unstable support surface was effective for activating the TrA muscle. García-Vaquero et al. ${ }^{14}$ claimed that bridge exercise supported by one leg increased the rotational torque of trunk and the activation of abdominal muscle. Next, Yoon et $a .^{6}$ reported that the bridge exercise affected the activation of the abdominal muscle while the hip was abducted by lifting one leg from an unstable support surface. While these results confirmed that specific abdominal muscles could be activated by the use

Copylight (C)2020 The Korean Society of Physical Therapy

This is an Open Access article distribute under the terms of the Creative Commons Attribution Non-commercial License (https:// creativecommons.org/license/by-nc/4.o.) which permits unrestricted non-commercial use, distribution, and reproduction in any medium, provided the original work is properly cited. 
of tools and changes in exercise methods, most previous studies have verified the change in activation of the muscle and not the change in the trunk muscle thickness, which is the morphological change of the trunk muscle by applying external resistance to the leg. The change in trunk muscle activity is important for the improvement of muscle strength. The study of muscle thickness, which is a morphological change confirmed by ultrasound, is also important in verifying the quantitative and qualitative information of muscle as well as evaluating and analyzing its functions. ${ }^{15}$

In response, this study attempted to confirm the changes on the thickness of trunk muscle by a bridge exercise accompanied by resistance to one hip adductor muscle using a resistance band, and it suggests the possibility of providing basic data for a bridge exercise and a lumbar stabilization exercise in clinical practice.

\section{METHODS}

\section{Subjects}

This study recruited 30 adult men and women as the experiment subjects through a recruitment announcement, and selected the population from adults who had no difficulties in bridge exercise, had no musculoskeletal disease, and those who did not exercise regularly. The subjects were divided into two exercise groups: 15 for Bridge Exercise Group (BEG) and 15 for One Hip joint Adduction Bridge Exercise Group (OHABEG), through a ramdomized test and by drawing lots. The sample size of the subjects was selected using $G^{*}$ power 3.1 based on preceding studies, at significance level $(\alpha=0.05)$, test power $(1-\beta=0.95)$, and effect size $(d=0.8)$. Since this resulted in 13 participants per group, the study recruited 30 people in total for 15 people in each by considering a 20\% elimination rate. After the objective of this study and the exercise method were explained to the subjects, those wishing to participate voluntarily signed a research consent form and participated in the study. The study also included a signed consent form, according to the ethical standards of the Declaration of Helsinki.

\section{Experimental methods}

This study used ultrasound imaging equipment (MylabOne, Esaote, ltaly) to measure the trunk muscle thickness by setting a frequency modulation range at $10 \mathrm{MHz}$, sensitivity $\mathrm{G} 60$, and dynamic range $\mathrm{C} 4$, using sufficient gel between the skin and transducer. To measure the change of thickness in EO abdominal muscle, IO abdominal muscle, and TrA muscle, this study drew a straight line outward from the navel and a straight line from the axilla and the anterior superior iliac spine, and marked the point where the two lines met with a pen. Considering that breathing affects changes in trunk muscle thickness, this study had the subjects stop breathing at the end of exhalation and measured their thickness at the same time. ${ }^{16}$ The thickness of ES muscle was measured 3 times by placing the transducer to a horizontal direction in the prone position and moving it $4 \mathrm{~cm}$ laterally in the spinous process of lumbar vertebra to verify the spinous and transverse processes, and the thickness was measured between the transverse processes in the fascia. Prior to the measurement, this study selected one physical therapist that had a strong anatomical knowledge and was skilled in using in sonography, measured the thickness of right trunk muscle 3 times, and used the average value.

\section{Procedure}

The warm-up postures for the bridge exercise applied to BEG and OHABEG were shoulder joint gathering, inner rotation, bending of elbow joint by $90^{\circ}$ to place hands on both shoulders of the opposite side to form an Xshaped posture, and bending of the knee joints by $130^{\circ}$. For an exercise method, this study alternatively applied the bridge exercise and consistent resistance to one hip joint adductor muscle of the subjects in OHABEG, by playing a stable column next to the exercise site. The resistance band was $30 \mathrm{~cm}$ long at a stable state, was applied $10 \mathrm{~cm}$ above the knee joint, and extended up to $60 \mathrm{~cm}$ by the tension as soon as the exercise started (Figure 1). The duration and time of exercise was 30 minutes a day, 3 times a week for a total of 8 weeks. As for exercise program, the subjects performed 5 minutes of light walking, 20 minutes of main exercise, and 5 minutes of stretching as a cool-down. The subjects carried out the bridge exercise using their one hip joint adduction for 20 seconds, followed by a 10 -second rest for 20 minutes of exercise in total. BEG performed a bridge

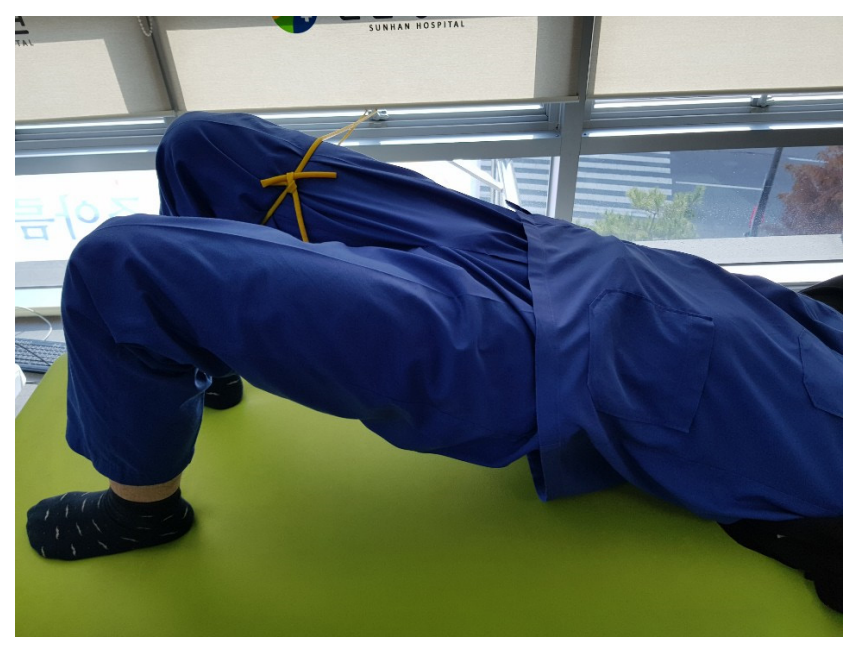

Figure 1. Bridge exercise with one hip joint adduction. 
exercise without resistance in the same method and application time as in OHABEG.

\section{Statistical analysis}

Data were analyzed using SPSS 19.0 for Windows (SPSS, Chicago, IL, USA). General features of the participants were detailed as means and standard deviations using descriptive statistics. The Shapiro-Wilk test was used to check the normal distribution of the data. Two-way repeated ANOVA was performed to check the thickness change before the exercise, 4 weeks after, and 8 weeks after for both groups, and the significance level was set to $\alpha=0.05$. In the case of interaction between time and the groups, a paired t-test was conducted to examine any intra-group changes, independent t-test to determine the inter-group difference, and a Bonferroni verification was performed considering type I error, ${ }^{17}$ and the significance level was set to $\alpha=0.01$.

\section{RESULTS}

\section{General characteristics of subjects}

In OHABEG, the average age was $23.2 \pm 2.6$ years, average height $169.2 \pm$

$9.7 \mathrm{~cm}$, and average weight $63.9 \pm 17.3 \mathrm{~kg}$. In BEG, the average age was 23.1 \pm 2.6 years old, average height $171.0 \pm 7.3 \mathrm{~cm}$, and the average weight was $67.3 \pm 12.7 \mathrm{~kg}$ (Table 1).

\section{Comparison of trunk muscle thickness}

The changes in the thickness of trunk muscle according to the exercise method are as follows. The EO abdominal, IO abdominal, and the TrA muscles showed a significant increase by period and time in intra-group interactions $(\mathrm{p}<0.05)$, while there was no significant difference in intergroup changes $(p>0.05)$. The ES muscle had a significant increase in each period $(\mathrm{p}<0.05)$ but no significant difference in time, intra-group interactions, and in inter-group changes ( $\mathrm{p}>0.05)$ (Tables 2, 3).

\section{DISCUSSION}

This study aimed to verify the effects of bridge exercise with resistance to one hip joint adductor muscle on the thickness of EO and IO abdominal muscles, TrA muscle, and erector spinae muscle. Then, the study measured the changes using ultrasound by dividing the period into before ex-

Table 1. General characteristics of subjects

$(n=30)$

\begin{tabular}{lccc}
\hline & OHABEG $(n=15)$ & BEG $(n=15)$ & $p$ \\
\hline Gender $(M / F)$ & $8 / 7$ & $8 / 7$ & \\
Age $(\mathrm{yr})$ & $23.20 \pm 2.59$ & $23.06 \pm 2.57$ & 0.337 \\
Height $(\mathrm{cm})$ & $169.20 \pm 9.65$ & $171.00 \pm 7.32$ & 0.494 \\
Weight $(\mathrm{kg})$ & $63.87 \pm 17.26$ & $67.34 \pm 12.67$ & 0.683 \\
\hline
\end{tabular}

Values are presented as mean \pm standard deviation.

OHABEG: one side hip joint adduction bridge exercise group, BEG: bridge exercise group.

Table 2. Comparison of trunk muscle thickness

$(\mathrm{mm})$

\begin{tabular}{|c|c|c|c|c|c|}
\hline & Pre & 4 weeks & 8 weeks & Source & $F(p)$ \\
\hline \multicolumn{6}{|l|}{ EO } \\
\hline OHABEG & $5.16 \pm 0.98$ & $5.76 \pm 0.96$ & $6.47 \pm 0.89$ & Time & $49.508(0.001)^{*}$ \\
\hline \multirow[t]{2}{*}{ BEG } & $5.24 \pm 1.18$ & $5.34 \pm 1.20$ & $5.50 \pm 1.15$ & Time $\times$ Group & $21.737(0.001)^{*}$ \\
\hline & & & & Group & $1.468(0.26)$ \\
\hline \multicolumn{6}{|l|}{10} \\
\hline OHABEG & $7.25 \pm 1.19$ & $7.89 \pm 1.26$ & $8.59 \pm 1.38$ & Time & $60.935(0.001)^{*}$ \\
\hline \multirow[t]{2}{*}{ BEG } & $7.44 \pm 1.41$ & $7.60 \pm 1.36$ & $7.79 \pm 1.34$ & Time $\times$ Group & $21.401(0.001)^{*}$ \\
\hline & & & & Group & $0.384(0.54)$ \\
\hline \multicolumn{6}{|l|}{$\operatorname{TrA}$} \\
\hline OHABEG & $3.17 \pm 0.84$ & $3.75 \pm 0.85$ & $4.46 \pm 0.90$ & Time & $55.693(0.001)^{*}$ \\
\hline \multirow[t]{2}{*}{ BEG } & $3.28 \pm 0.54$ & $3.56 \pm 0.60$ & $3.81 \pm 0.68$ & Time $\times$ Group & $12.791(0.001)^{*}$ \\
\hline & & & & Group & $0.843(0.36)$ \\
\hline \multicolumn{6}{|l|}{ ES } \\
\hline OHABEG & $20.05 \pm 1.40$ & $20.93 \pm 1.47$ & $21.64 \pm 1.38$ & Time & $47.608(0.001)^{*}$ \\
\hline \multirow[t]{2}{*}{ BEG } & $19.99 \pm 0.95$ & $20.42 \pm 0.92$ & $20.98 \pm 1.20$ & Time $\times$ Group & $3.022(0.06)$ \\
\hline & & & & Group & $0.888(0.35)$ \\
\hline
\end{tabular}

Values are presented as mean \pm standard deviation.

OHABEG: one side hip joint adduction bridge exercise group, BEG: bridge exercise group, EOT: external oblique, IO: internal oblique, TrA: transverse abdominis, ES: erector spinae.

${ }^{*} p<0.01$. 
Table 3. Intra-group changes and inter-group changes

$(\mathrm{mm})$

\begin{tabular}{lccc}
\hline & After 4 weeks $^{\mathrm{a}}$ & ${\text { After } 8 \text { weeks }^{\mathrm{b}}} \mathrm{t}(\mathrm{p})$ \\
\hline EO & & & \\
OHABEG & $0.60 \pm 0.31$ & $1.31 \pm 0.49$ & $10.342(0.001)^{*}$ \\
BEG & $0.10 \pm 0.16$ & $0.26 \pm 0.35$ & $2.816(0.01)^{*}$ \\
$\mathrm{t}(\mathrm{p})$ & $1.006(0.29)$ & $2.581(0.01)^{*}$ & \\
IO & & & \\
OHABEG & $0.63 \pm 0.23$ & $1.33 \pm 0.50$ & $10.245(0.001)^{*}$ \\
BEG & $0.16 \pm 0.14$ & $0.34 \pm 0.33$ & $3.961(0.001)^{*}$ \\
t (p) & $0.590(0.55)$ & $1.606(0.12)$ & \\
TrA & & & \\
OHABEG & $0.58 \pm 0.25$ & $1.29 \pm 0.48$ & $10.287(0.001)^{*}$ \\
BEG & $0.28 \pm 0.32$ & $0.53 \pm 0.49$ & $4.230(0.001)^{*}$ \\
t (p) & $0.700(0.48)$ & $2.211(0.03)$ & \\
\hline
\end{tabular}

Values are presented as mean \pm standard deviation.

OHABEG: one side hip joint adduction bridge exercise group, BEG: bridge exercise group, EOT: external oblique, IO: internal oblique, TrA: transverse abdominis, ES: erector spinae.

${ }^{a}$ Difference between pre and 4 weeks, ${ }^{b}$ Difference between pre and 8 weeks. ${ }^{*} p<0.01$.

ercise, 4 weeks after, and 8 weeks after. The thickness of EO abdominal muscle, IO abdominal muscle, and TrA muscle increased significantly by period, time, and inter-group interaction, and ES muscle increased significantly only by period according to the study results.

A research confirming the change of trunk muscle through the change of leg position reported that contraction of hip joint adductor muscle in a standing position contracted TrA muscle, thereby increasing the thickness of TrA muscle. ${ }^{18}$ Lee et al. ${ }^{19}$ argued that in a bridge exercise using sling and by gathering and opening the hip joint, the contraction of hip joint adductor muscle increased the muscle activity of rectus abdominis (RA) muscle, TrA muscle, and ES muscle. In addition, $\mathrm{Na}$ et al. ${ }^{20}$ reported that the simultaneous contraction of hip joint adductor muscle with a bridge exercise increased the muscle activity of IO abdominal muscle but had no change in ES muscle. Kim et al. ${ }^{21}$ claimed that exercise using the contraction of hip joint adductor muscle affected the muscle activity of RA muscle, EO abdominal muscle, and IO abdominal muscle, even in a plank exercise which is a different method, and had the same results as the findings of this study.

Located in the front of thigh, hip joint adductor muscle consists of pectineal muscle, gracilis muscle, adductor magnus muscle, adductor brevis muscle, and adductor longus muscle. ${ }^{22}$ As for adults, it occupies $1 / 4$ of the leg muscle and is known to affect the movements of hip joint and pelvis. ${ }^{22}$ The contraction of hip joint adductor muscle plays an important role in increasing the stability of the lower back area, since it contracts the abdominal muscle and pelvic muscle and the exercise using adductor muscle acts as a key factor in increasing the intra-abdominal pressure. ${ }^{23}$

Considering how hip joint adductor muscle affects abdominal muscle, the contraction of hip joint adductor muscle induces the contraction of lumbar pelvic muscle and the TrA muscle on the iliac crest, which cause the first force to pull toward the spine and the second force at the same time as the pelvic ligament contracts, making the two forces to tighten the ilium and sacrum. ${ }^{18}$ This increases the stability of trunk and pelvis and contracts the surrounding muscles. ${ }^{24}$ Moreover, since the hip joint adductor muscle is attached around pubic symphysis, the contraction of adductor muscle induces torsion in the pelvis and creates instability, inducing the contraction of TrA muscle and IO abdominal muscle on pelvis to reduce instability. The increase in EO abdominal muscle is due to an exercise using resistance. Applying trunk external force on one side causes the instability of trunk, and the EO abdominal muscle on the opposite side of resistance contracts to reduce instability, and as result, muscle thickness increases.

There is no difference in ES because of the effects and exercise method of bridge exercise. Since a bridge exercise is applied to strengthen hip joint extension muscle and lower back muscle, it showed effects on the ES muscle in BEG only by period at the same time as it was performed.

It is known that putting the abdomen in during a bridge exercise causes a decrease in the muscle activity of ES. ${ }^{25}$ It is considered that this result was caused by the decrease of ES contraction than abdominal muscle contraction, while maintaining the neutral posture of hip joint during a bridge exercise in this study. In addition, the arm was placed on the shoulder during the bridge exercise, so that the area of the body and the support area of the floor surface were reduced, causing the resistance to the hip joint adduction due to the instability of trunk. As a result, abdominal muscles contracted more than the ES to decrease the instability of trunk. This study examined the intragroup and intergroup changes after 4 and 8 weeks based on the time period and interactions between groups. For intragroup changes, there was a significant increase in groups OHABEG and BEG. However, OHABEG had more significant increase than BEG, which indicates that the bridge exercise applying resistance on one hip joint adductor muscle can effectively increase muscle thickness. As for inter-group changes, there was a difference between the groups only in the EO abdominal muscle after 8 weeks, as the contraction ratio of the EO abdominal muscle increased due to the instability created by the small support area and external resistance. ${ }^{26}$

A limitation of this study is that it is difficult to generalize the results because it did not target all age groups in their early 20 , had a small num- 
ber of subjects, and limited the scope to trunk muscles without checking the thickness of leg muscles. However, the change in trunk muscle thickness is regarded positive, and a qualitative research will be necessary in the future by diversifying muscle characteristics and various postures not identified in this study. In conclusion, this study suggests the possibility of using a bridge exercise as a rehabilitation treatment for lumbar stabilization and basic data in clinical practice, since bridge exercise accompanied by one hip joint adduction increases the thickness of EO, IO, and TrA in healthy adults.

\section{REFERENCES}

1. Kang SY, Choung SD, Jeon HS. Modifying the hip abduction angle during bridging exercise can facilitate gluteus maximus activity. Man Ther. 2016;22:211-5.

2. Lim JH. Effects of flexible pole training combined with lumbar stabilization on trunk muscles activation in healthy adults. J Kor Phys Ther. 2018;30(1):1-7.

3. Borghuis J, Hof AL, Lemmink KA. The importance of sensory-motor control in providing core stability. Sports Med. 2008;38(11):893-916.

4. Alentorn-Geli E, Myer GD, Silvers HJ et al. Prevention of non-contact anterior cruciate ligament injuries in soccer players. Part 1: Mechanisms of injury and underlying risk factors. Knee Surgery Sports Traumatol Arthrosc. 2009;17(7):705-29.

5. Kim BR, Park SW, Lee HS. Effects of lumbar stabilization exercise program on the ratio of abdominal and back muscle strength in white collar workers. J Kor Phys Ther. 2015;27(6):419-24.

6. Yoon JO, Kang MH, Kim JS et al. Effect of modified bridge exercise on trunk muscle activity in healthy adults: a cross sectional study. Braz J Phys Ther. 2018;22(2):161-7.

7. Narouei S, hossein Barati A, Akuzawa H et al. Effects of core stabilization exercises on thickness and activity of trunk and hip muscles in subjects with nonspecific chronic low back pain. J Bodyw Mov Ther. 2020;24(4): 138-46.

8. Sipaviciene S, Kliziene I. Effect of different exercise programs on nonspecific chronic low back pain and disability in people who perform sedentary work. Clin Biomech. 2020;73:17-27.

9. Park KN, Kwon OY, Yi CH et al. Effects of motor control exercise vs muscle stretching exercise on reducing compensatory lumbopelvic motions and low back pain: a randomized trial. J Manipulative Physiol Ther. 2016;39(8):576-85.

10. Song GB, Heo JY. The effects of bridge exercise with abdominal drawing-in on balance in patients with stroke. J Kor Phys Ther. 2016;28(1):17 .

11. Lehman GJ, Hoda W, Oliver S. Trunk muscle activity during bridging exercises on and off a Swissball. Chiropr Osteopat. 2005;13(1):14-21.

12. Patti A, Bianco A, Karsten B et al. The effects of physical training without equipment on pain perception and balance in the elderly: A randomized controlled trial. Work. 2017;57(1):23-30.

13. Saliba SA, Croy T, Guthrie R et al. Differences in transverse abdominis activation with stable and unstable bridging exercises in individuals with low back pain. N Am J Sports Phys Ther. 2010;5(2):63-73.

14. García-Vaquero MP, Moreside JM, Brontons-Gil E et al. Trunk muscle activation during stabilization exercises with single and double leg support. J Electromyogr Kinesiol. 2012;22(3):398-406.

15. Bilodeau M, Schindler-Ivens S, Williams R et al. EMG frequency content changes with increasing force and during fatigue in the quadriceps femoris muscle of men and women. J Electromyo Kinesiol. 2003;13(1):8392.

16. Hodges PW, Gandevia SC. Changes in intra-abdominal pressure during postural and respiratory activation of the human diaphragm. J Appl Physiol. 2000;89(3):967-76.

17. Jung DY, Koh EK, Kwon OY et al. Effect of medial arch support on displacement of the myotendinous junction of the gastrocnemius during standing wall stretching. J Orthop Sports Phys Ther. 2009;39(12):86774 .

18. Moon HJ, Goo BO. The effect of change in transversus abdominis thickness using ultrasound image during a hip adductor contraction. J Korean Soc Phys Med. 2011;6(3):287-92.

19. Lee DH, Lee SY, Park JS et al. The effect of height of hip joint abductionadduction and sling on transverse abdominis, rectus abdominis, and erector spinae muscles activities during bridging exercise with sling. J Korean Soc Neur Ther. 2016;20(3):23-6.

20. Na SW, Oh DW, Park HJ. Effect of hip adductor co-contraction on trunk muscle activation during bridge exercise in healthy young individuals. J Korean Soc Phys Med. 2012;7(3):275-82.

21. Kim SY, Kang MH, Kim ER et al. Comparison of EMG activity on abdominal muscles during plank exercise with unilateral and bilateral additional isometric hip adduction. J Electromyogr Kinesiol. 2016;30:9-14.

22. Hrysomallis C. Hip adductors' strength, flexibility, and injury risk. J Strength Cond Res. 2009;23(5):1514-7.

23. Hemborg B, Moritz U, Hamberg J et al. Intraabdominal pressure and trunk muscle activity during lifting--effect of abdominal muscle training in healthy subjects. Scand J Rehabil Med. 1983;15(4):183-96.

24. Van Dijke GAH, Snijders CJ, Stoeckart R et al. A biomechanical model on muscle forces in the transfer of spinal load to the pelvis and legs. J Biomech. 1999;32(9):927-33.

25. Koh EK, Jang JH, Jung DY. Effect of abdominal hollowing on muscle activity of gluteus maximus and erector spinae during bridging exercise. J Kor Phys Ther. 2012;24(5):319-24.

26. Vera-Garcia FJ, Grenier SG, McGill SM. Abdominal muscle response during curl-ups on both stable and labile surfaces. Phys Ther. 2000;80 (6):564-9. 